\title{
Extensão Universitária: Avaliar para evoluir
}

\section{University Extension: Evaluate to evolve}

\author{
Taiani Bacchi Kienetz \\ Universidade Federal de Santa Maria - UFSM - Brasil \\ taianibk@gmail.com \\ ORCID: 0000-0002-7760-3737 \\ Kelmara Mendes Vieira \\ Universidade Federal de Santa Maria - UFSM - Brasil \\ kelmara@terra.com.br \\ ORCID: 0000-0002-8847-0941 \\ Monize Sâmara Visentini \\ Universidade Federal da Fronteira Sul - UFFS - Brasil \\ monize.visentini@uffs.edu.br \\ ORCID: 0000-0001-6233-6106
}

Submetido em 06/10/2019; Aprovado em 24/12/2019.

\begin{abstract}
Resumo
Objetivo: Dentre os três pilares do ensino superior, a extensão é o mais carente de um sistema de avaliação. A construção de sistemas de avaliação e indicadores para a extensão perpassa pela necessidade de avaliação por diferentes atores sociais nas diversas etapas do processo. Este trabalho propõe um instrumento multidimensional de avaliação da extensão, considerando diversas etapas do processo (registro, avaliação e acompanhamento da ação), tendo em vista a percepção dos diferentes atores envolvidos. Metodologia: Aplicou-se uma observação estruturada em 63 sites de universidades federais brasileiras não sendo possível identificar modelos de indicadores já consolidados para as avaliações das ações de Extensão. Principais Resultados: Assim, foi proposto o instrumento composto de 3 dimensões, 12 critérios de análise e 43 questões. Contribuições Práticas: 0 instrumento pode ser aplicado tanto às instituições de ensino superiores públicas quanto privadas; permitindo a avaliação ao longo de todo o processo e; identificando a percepção tanto dos agentes internos envolvidos quanto da sociedade atendida.
\end{abstract}

Palavras-chaves: Instituições de Ensino; Instrumentos de Avaliação; Atores Sociais.

\begin{abstract}
Objective: Among the three pillars of higher education, extension is the most lacking in an evaluation system. The construction of evaluation systems and indicators for extension goes through the need for evaluation at different stages of the process and from different social actors. This paper proposes a multidimensional extension assessment tool, considering several process steps (recording, evaluation, and monitoring of the action), taking into account the perception of the different actors involved. Methodology: A structured observation was applied to 63 sites of Brazilian federal universities and it was not possible to identify models of indicators already consolidated for the evaluation of Extension actions. Main Results: Thus, the instrument composed of 3 dimensions, 12 analysis criteria, and 43 questions was proposed. Practical Contributions: The instrument can be applied to both public and private higher education institutions; allowing evaluation throughout the process and; identifying the perception of both the internal agents involved and the society served.
\end{abstract}

Keywords: Educational institutions; Evaluation instruments; Social actors.

\section{Introdução}

As instituições de ensino superior estão alicerçadas sob o princípio da indissociabilidade entre ensino, pesquisa e extensão. Uma das finalidades do ensino superior é promover a extensão, aberta à participação da população, visando à difusão das conquistas e benefícios resultantes da criação cultural 
e da pesquisa científica e tecnológica geradas na instituição (Brasil, 1988). Entretanto, um dos empecilhos encontrados para o fomento da extensão é que esta não compõe a matriz da Associação Nacional dos Dirigentes das Instituições Federais de Ensino Superior - ANDIFES, não obtendo uma destinação de recurso específica. E, uma das dificuldades enfrentadas para a composição dessa matriz é o estabelecimento de critérios de monitoramento e avaliação da extensão.

O monitoramento e a avaliação estão no cerne da formulação de políticas com base em evidências, pois fornecem as ferramentas para que as partes interessadas possam ponderar a qualidade, a eficiência e a efetividade, com foco em resultados (Gertler et al., 2015). Avaliações dessa natureza exigem técnicas de mensuração e indicadores apropriados. Dentre as principais técnicas de avaliação da eficiência da educação superior tem-se a Análise Envoltória de Dados (Zoghbi et al., 2013) e a fronteira estocástica, as quais podem ser estimadas em diferentes softwares (Pereira, 2015), mas necessitam de indicadores como medidas de performance. A elaboração desses indicadores é essencial para a determinação da eficiência do setor público, tanto do ponto de vista técnico quanto do social (Matos e Terra, 2015).

Os indicadores são instrumentos de gestão essenciais nas atividades de monitoramento e avaliação das organizações, assim como dos seus projetos, programas e políticas, pois permitem acompanhar o alcance das metas, identificar avanços, melhorias de qualidade, correção de problemas e necessidades de mudança (Veras, 2014). Especialmente, os indicadores de avaliação permitem descrever, por meio da geração de informações, o estado real dos acontecimentos e seus comportamentos e analisar as informações presentes de forma a realizar proposições de valor.

Para viabilizar o mapeamento das ações de extensão a partir de indicadores, é preciso que estes contemplem as atividades desenvolvidas no âmbito de cada instituição e sejam passíveis de consolidação e comparação no âmbito nacional. Nesse sentido, o Fórum de Pró-Reitores de Extensão das Instituições Públicas de Educação Superior Brasileiras sugere indicadores relativos ao compromisso institucional e aos impactos sociais (Fórum de Pró-Reitores das Instituições Públicas de Educação Superior Brasileiras [FORPROEX], 2001). Assim, faz-se necessário considerar os perfis de ações desenvolvidas e a percepção das partes interessadas das ações sobre os seus efeitos e produtos gerados. Entende-se por partes interessadas aqueles atores (coordenador, bolsistas, público-alvo, instituição promotora e/ou apoiadora da ação) que participam ativamente no projeto ou têm interesses que possam ser afetados pelo desempenho do projeto.

Portanto, entende-se que para as políticas de extensão evoluírem, um passo fundamental é a criação de instrumentos de avaliação. Assim, este trabalho propõe um instrumento multidimensional de avaliação da extensão universitária, abarcando os processos de registro, avaliação da submissão e acompanhamento da ação, considerando a percepção dos diferentes atores envolvidos (gestor institucional, coordenador do projeto, acadêmicos e comunidade participante).

\section{Contexto da realidade investigada}

Em 2010, o Governo Federal, através do Decreto n 7.233/2010, assinalou a possibilidade de destinação orçamentária e financeira para o fomento da extensão universitária dentro do orçamento das IES, a partir de programas de extensão institucionais, vinculando esta condição à existência de indicadores de monitoramento, o que até o presente momento não foi aplicado em termos práticos devido, justamente, à inexistência dos indicadores.

Mais recentemente, a Lei no 13.005, de 25 de junho de 2014, que aprovou o Plano Nacional de Educação 2011-2020, determinou que seja assegurado, no mínimo, dez por cento do total de créditos curriculares exigidos para a graduação em programas e projetos de extensão universitária, orientando sua ação, prioritariamente, para áreas de grande pertinência social. Entretanto, até agora, a maioria das instituições ainda não adaptou seus projetos políticos pedagógicos à legislação.

Entende-se que para que seja possível elevar a Extensão ao mesmo patamar do Ensino e da Pesquisa, que juntos formam o tripé no qual a universidade está alicerçada, é imprescindível que se avance no desenvolvimento e implantação de modelos de avaliação para a extensão. Para que as ações de Extensão se desenvolvam é preciso tornar permanente a avaliação institucional das atividades de Extensão como um dos parâmetros de avaliação da própria Universidade (Política Nacional de Extensão Universitária, 2012).

\section{Diagnóstico da situação problema}

A ausência de critérios claros para valorar as ações extensionistas e reconhecer os esforços a elas 
vinculados pode ser uma das causas que expliquem um menor número de docentes desenvolvendo tais práticas. A baixa adesão à extensão acaba por limitar a atuação da universidade ante a sociedade, enquanto que o fortalecimento da extensão tende a gerar como benefício um maior intercâmbio com a sociedade (Política Nacional de Extensão Universitária, 2012).

A curricularização da extensão, destinação de $10 \%$ dos créditos dos cursos de graduação para ações de extensão, que deverá ocorrer até 2020, estreita a ligação entre Ensino e Extensão e exigirá uma maior participação docente e recursos financeiros para abarcar um maior volume de estudantes que participarão dessas atividades. Entretanto, sem a construção de um sistema de avaliação que permita o registro, acompanhamento e avaliação dos resultados, dificilmente, as instituições de ensino terão condições de incentivar a participação dos docentes e discentes e de valorizar a extensão.

Além disso, no cenário atual tem-se um ciclo vicioso em que a extensão não se desenvolve porque não está presente na matriz orçamentária, mas não está na matriz porque não possui indicadores para avaliação de resultados. Portanto, entende-se que a criação e implantação de sistemas de avaliação internos seja um primeiro passo, para que no futuro, possa-se ter um conjunto de indicadores capazes de quebrar tal ciclo.

\section{Análise da situação problema}

O levantamento dos dados da extensão no Brasil foi realizado a partir da verificação dos sites institucionais de 63 universidades federais, divulgadas pela "Lista de Instituições Federais, Estaduais e Municipais ligadas ao Fórum de Pró-Reitores de Extensão das Instituições de Educação Superior Brasileiras - FORPROEX Nacional" disponível no site da Rede Nacional de Extensão (RENEX). Com base em observação estruturada, guiada pelo roteiro de questões apresentado na Tabela 1 , analisaram-se 5 categorias: Registro, Editais, Avaliação, Acompanhamento e Curricularização.

Para as questões das categorias Registro, Avaliação, Acompanhamento e Curricularização foram definidos dois tipos de respostas para tabulação dos resultados, sendo elas: "Sim" ou "Não Identificado", exceto para a questão 1, que poderia ser assinalada também como a resposta "Não". Para as questões das categorias Editais também foram definidos dois tipos de respostas para tabulação dos resultados, sendo elas: "Sim" ou "Não", exceto para a questão 7, cujas respostas deveriam enquadrar-se como "Sim" ou "Não Identificado", observando editais lançados no período compreendido entre os anos de 2015 e 2017.

Tabela 1. Categorias e questões analisadas e análise descritiva da amostra

\begin{tabular}{|c|c|c|c|c|c|c|c|}
\hline \multirow[t]{2}{*}{ Categorias } & \multirow[t]{2}{*}{ Questões } & \multicolumn{2}{|c|}{ Sim } & \multicolumn{2}{|c|}{ Não } & \multicolumn{2}{|c|}{$\begin{array}{l}\text { Não Identi- } \\
\text { ficado }\end{array}$} \\
\hline & & Qtd. & $\%$ & Qtd. & $\%$ & Qtd. & $\%$ \\
\hline \multirow[t]{6}{*}{ Registro } & $\begin{array}{l}\text { 1.Possui Sistema próprio para registro das ações de exten- } \\
\text { são? }\end{array}$ & 17 & 27 & 38 & 60 & 8 & 13 \\
\hline & 2.Possui Política de Extensão? & 11 & 17 & $\mathrm{~N} / \mathrm{P}$ & $\mathrm{N} / \mathrm{P}$ & 52 & 83 \\
\hline & $\begin{array}{l}\text { 3.Possui Resolução regulamentando as atividades de Exten- } \\
\text { são? }\end{array}$ & 54 & 86 & $\mathrm{~N} / \mathrm{P}$ & $\mathrm{N} / \mathrm{P}$ & 9 & 14 \\
\hline & 4.Existem prazos definidos para registro de ações? & 4 & 6 & $\mathrm{~N} / \mathrm{P}$ & $\mathrm{N} / \mathrm{P}$ & 59 & 94 \\
\hline & 5.Existe formulário próprio para registro das ações? & 49 & 78 & $\mathrm{~N} / \mathrm{P}$ & $\mathrm{N} / \mathrm{P}$ & 14 & 22 \\
\hline & 6.Existe alguma condição para emissão de certificado? & 37 & 59 & $\mathrm{~N} / \mathrm{P}$ & $\mathrm{N} / \mathrm{P}$ & 26 & 41 \\
\hline \multirow[t]{9}{*}{ Editais } & 7.Possui Edital de Fomento interno à extensão? & 58 & 92 & $\mathrm{~N} / \mathrm{P}$ & $\mathrm{N} / \mathrm{P}$ & 5 & 8 \\
\hline & $\begin{array}{l}\text { 8.Existe formulário próprio para submissão das ações nos } \\
\text { Editais?* }^{\text {Edaio }}\end{array}$ & 54 & 93 & 4 & 7 & $\mathrm{~N} / \mathrm{P}$ & $\mathrm{N} / \mathrm{P}$ \\
\hline & $\begin{array}{l}\text { 9.Existem restrições quanto às rubricas disponibilizadas nos } \\
\text { editais?* }\end{array}$ & 54 & 93 & 4 & 7 & $\mathrm{~N} / \mathrm{P}$ & $\mathrm{N} / \mathrm{P}$ \\
\hline & 10.Existe priorização de algum tipo de ação para o fomento?* & 4 & 7 & 54 & 93 & $\mathrm{~N} / \mathrm{P}$ & $\mathrm{N} / \mathrm{P}$ \\
\hline & 11.Existe alguma condição para pagamento das bolsas?* & 27 & 47 & 31 & 53 & $\mathrm{~N} / \mathrm{P}$ & $\mathrm{N} / \mathrm{P}$ \\
\hline & $\begin{array}{l}\text { 12.Existe definição sobre quem pode ser coordenador de pro- } \\
\text { jeto?* }\end{array}$ & 55 & 95 & 3 & 5 & $\mathrm{~N} / \mathrm{P}$ & $\mathrm{N} / \mathrm{P}$ \\
\hline & 13.Existe exigência de emissão de relatório parcial?* & 36 & 62 & 22 & 38 & $\mathrm{~N} / \mathrm{P}$ & $\mathrm{N} / \mathrm{P}$ \\
\hline & 14.Existe exigência de emissão de relatório final?** & 51 & 88 & 7 & 12 & $\mathrm{~N} / \mathrm{P}$ & $\mathrm{N} / \mathrm{P}$ \\
\hline & $\begin{array}{l}\text { 15.Existe formulário para emissão de relatório (parcial ou fi- } \\
\text { nal) } ?^{*}\end{array}$ & 25 & 43 & 33 & 57 & $\mathrm{~N} / \mathrm{P}$ & $\mathrm{N} / \mathrm{P}$ \\
\hline
\end{tabular}




\begin{tabular}{|c|c|c|c|c|c|c|c|}
\hline \multirow[t]{10}{*}{ Avaliação } & $\begin{array}{l}\text { 16.Existe critério pontuável para análise das ações no regis- } \\
\text { tro? }\end{array}$ & 6 & 10 & $\mathrm{~N} / \mathrm{P}$ & $\mathrm{N} / \mathrm{P}$ & 57 & 90 \\
\hline & $\begin{array}{l}\text { 17.Existe critério pontuável para avaliação das ações nos } \\
\text { editais?* }\end{array}$ & 46 & 79 & $\mathrm{~N} / \mathrm{P}$ & $\mathrm{N} / \mathrm{P}$ & 12 & 21 \\
\hline & 18.Existe formulário próprio para avaliação dos Bolsistas?* & 9 & 16 & $\mathrm{~N} / \mathrm{P}$ & $\mathrm{N} / \mathrm{P}$ & 49 & 84 \\
\hline & $\begin{array}{l}\text { 19.Existe critério pontuável para a avaliação da participação } \\
\text { dos Bolsistas?* }\end{array}$ & 0 & 0 & $\mathrm{~N} / \mathrm{P}$ & $\mathrm{N} / \mathrm{P}$ & 58 & 100 \\
\hline & 20.Bolsistas realizam avaliação da ação de extensão?* & 42 & 72 & $\mathrm{~N} / \mathrm{P}$ & $\mathrm{N} / \mathrm{P}$ & 16 & 28 \\
\hline & $\begin{array}{l}\text { 21.Existe formulário próprio para avaliação da ação pelos } \\
\text { Bolsistas?* }\end{array}$ & 20 & 34 & $\mathrm{~N} / \mathrm{P}$ & $\mathrm{N} / \mathrm{P}$ & 38 & 66 \\
\hline & $\begin{array}{l}\text { 22.Existem critérios definidos para a avaliação da ação pelos } \\
\text { Bolsistas?* }\end{array}$ & 7 & 12 & $\mathrm{~N} / \mathrm{P}$ & $\mathrm{N} / \mathrm{P}$ & 51 & 88 \\
\hline & 23.Público-alvo realiza avaliação da ação de extensão? & 1 & 2 & $\mathrm{~N} / \mathrm{P}$ & $\mathrm{N} / \mathrm{P}$ & 62 & 98 \\
\hline & $\begin{array}{l}\text { 24.Existe formulário próprio para avaliação da ação pelo Pú- } \\
\text { blico-Alvo? }\end{array}$ & 0 & 0 & $\mathrm{~N} / \mathrm{P}$ & $\mathrm{N} / \mathrm{P}$ & 63 & 100 \\
\hline & $\begin{array}{l}\text { 25.Existem critérios definidos para a avaliação da ação pelo } \\
\text { Público-Alvo? }\end{array}$ & 0 & 0 & $\mathrm{~N} / \mathrm{P}$ & $\mathrm{N} / \mathrm{P}$ & 63 & 100 \\
\hline \multirow[t]{3}{*}{ Acompanhamento } & 26.Existe exigência de emissão de relatório parcial? & 42 & 67 & $\mathrm{~N} / \mathrm{P}$ & $\mathrm{N} / \mathrm{P}$ & 21 & 33 \\
\hline & 27.Existe exigência de emissão de relatório final? & 53 & 84 & $\mathrm{~N} / \mathrm{P}$ & $\mathrm{N} / \mathrm{P}$ & 10 & 16 \\
\hline & $\begin{array}{l}\text { 28.Existe formulário para emissão de relatório (parcial ou fi- } \\
\text { nal)? }\end{array}$ & 36 & 57 & $\mathrm{~N} / \mathrm{P}$ & $\mathrm{N} / \mathrm{P}$ & 27 & 43 \\
\hline Curricularização & $\begin{array}{l}\text { 29.Possui regramento para a atividade Curricularização de } \\
\text { Extensão? }\end{array}$ & 9 & 14 & $\mathrm{~N} / \mathrm{P}$ & $\mathrm{N} / \mathrm{P}$ & 54 & 86 \\
\hline
\end{tabular}

Fonte: Elaborada pelas autoras (2019)

Nota: N/P - escala não pertence à questão; *Neste caso houve 5 IES em que não se identificou editais de fomento

Em relação à categoria Registro, identificou-se que a maioria das IES (60\%) não possui sistema próprio para registro de ações nem Política de Extensão (83\%), contudo possui resolução que regula as atividades de Extensão (86\%). Praticamente inexiste a fixação de datas para o registro, porém a não fixação de prazos específicos não determina que não existam datas de submissão, pois 14 destas instituições adotam um edital de fluxo contínuo, garantindo períodos para submissão e períodos para avaliação. Verifica-se que esta pode ser uma maneira de sistematizar melhor o fluxo de trabalho de proponentes e avaliadores. Aferiu-se que a adoção de formulários próprios para o registro das ações, bem como a fixação de condições para emissões de certificado são práticas da maioria sendo adotados por, respectivamente, $78 \%$ e $59 \%$.

Os dados da categoria Editais assinalam a existência de fomento em 92\% das IES, bem como a utilização de formulários para a realização das submissões de candidaturas e adoção de restrições quanto às rubricas facultadas por $93 \%$ das universidades. Somente quatro instituições adotam algum critério de priorização em seus Editais; já quanto ao pagamento de bolsas, existe um equilíbrio entre as universidades que definem condições para recebimento (47\%) e as que não expõem (53\%). Os editais (95\%) determinam quem são os sujeitos aptos a coordenação de projeto. Por fim, verifica-se a exigência de relatórios parciais e finais na maioria das instituições ainda que a minoria (43\%) adote um formulário padrão para a emissão destes.

Quanto à Avaliação, identifica-se que apenas 6 IES possuem critérios pontuáveis para o registro da ação, enquanto que 46 editais adotam critérios pontuáveis em suas avaliações. Verifica-se que a adoção de formulário para avaliação dos bolsistas acontece em somente nove, sendo que nenhuma adota critérios pontuáveis. Como contraponto, $72 \%$ dos bolsistas realizam avaliação das ações de Extensão, ainda que poucos Editais predeterminem os formulários (34\%) e critérios (10\%). Ainda, em somente uma instituição foi identificada a necessidade de realização de avaliação por parte do público, embora inexista formulário próprio ou critérios que guiem esta prática.

Na categoria Acompanhamento, a maioria exige a emissão de relatórios parciais (67\%) e finais (84\%) e tem formulários padronizados para que estes sejam realizados (57\%). A obrigação destes relatórios em formulários padrões permite a comparabilidade dos dados, desde que estabelecidos critérios para acompanhar a evolução da ação no decorrer do tempo e dos recursos empregados. Por fim, na categoria Curricularização, percebe-se que somente $14 \%$ das instituições possuem regulamentação destas atividades. 


\section{Proposição de um modelo multidimensional de avaliação de extensão}

Para a construção do modelo, além da análise dos dados referentes à extensão nas IES brasileiras foram realizadas 16 entrevistas, com representantes das diferentes partes interessadas e que atuam em diversos níveis de gestão da extensão universitária. 0 roteiro de entrevista foi estruturado de maneira que permitisse compreender a experiência dos entrevistados a respeito dos processos internos e questões financeiras, assim como a percepção destes em relação a relevância e o papel das demais partes interessadas nas ações extensionistas, ou seja, os acadêmicos (bolsistas e voluntários) e a comunidade beneficiada pela ação.

As quatro perspectivas (processos internos, aprendizado e crescimento, financeira e cliente) do Balanced Scorecard (BSC) foram utilizadas como parâmetro para a subdivisão das entrevistas. Optou-se pela utilização do BSC em detrimento de outras metodologias, visto que se considerou que a integração entre indicadores financeiros e não financeiros adotada por esta metodologia e o fato de utilizar quatro perspectivas, que permitem uma adequada aplicação e enquadramento ao contexto atual da Extensão Universitária brasileira, favoreceriam a elaboração de um modelo que abrangesse as questões e partes relativas à temática extensionista na gestão pública.

Os resultados das entrevistas indicaram lacunas que orientaram a proposição do modelo multidimensional. A definição das três dimensões de análise (Registro da Ação, Avaliação da Submissão e Acompanhamento da Submissão) levou em consideração os procedimentos sugeridos pelos entrevistados, bem como os fluxos observados na etapa de avaliação da extensão. A realização das entrevistas também subsidiou a atribuição dos pesos (Quadro 1) e dos parâmetros de categorização (Figura 1) do modelo. A atribuição dos pesos foi realizada, prioritariamente, a partir da importância expressada por esses entrevistados para os critérios de avaliação, e tiveram como objetivo ponderar a análise para privilegiar os parâmetros que devem ser priorizados no momento da avaliação Os itens inerentes aos parâmetros mais citados e declarados como de grande importância para a avaliação da extensão receberam pesos 1,5 e 1,0, aos demais itens foi atribuído o peso 0,5.

Quadro 1. Dimensões (Dim.), critérios, questões e pesos para o modelo multidimensional proposto.

\begin{tabular}{|c|c|c|c|}
\hline Dim. & Critérios & Questões para análise & Peso \\
\hline \multirow{17}{*}{ 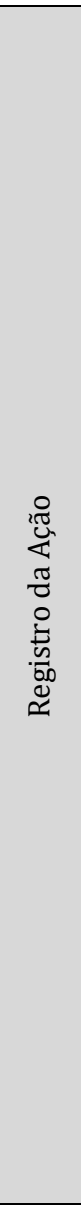 } & \multirow{4}{*}{$\begin{array}{l}\text { Impacto e transforma- } \\
\text { ção social }\end{array}$} & $\begin{array}{l}\text { 1.A proposta descreve as contribuições para a superação dos problemas sociais } \\
\text { visando à emancipação dos sujeitos? }\end{array}$ & 0,5 \\
\hline & & $\begin{array}{l}\text { 2.A proposta prevê a geração de produtos visando à ampliação de oportunidades ed- } \\
\text { ucacionais? }\end{array}$ & 0,5 \\
\hline & & $\begin{array}{l}\text { 3.A proposta indica as características socioeconômicas, culturais e políticas dos bene- } \\
\text { ficiários? }\end{array}$ & 0,5 \\
\hline & & $\begin{array}{l}\text { 4.A proposta indicou a metodologia utilizada para estimativa do número de pessoas } \\
\text { beneficiadas coerente com o quantitativo apontado? }\end{array}$ & 0,5 \\
\hline & \multirow{4}{*}{$\begin{array}{l}\text { Impacto na Formação } \\
\text { do Estudante }\end{array}$} & $\begin{array}{l}\text { 5.0s resultados técnicos/científicos esperados na formação profissional estão explic- } \\
\text { itados? }\end{array}$ & 0,5 \\
\hline & & 6.0s resultados sociais esperados na formação cidadã estão explicitados? & 0,5 \\
\hline & & $\begin{array}{l}\text { 7.A proposta descreve como os estudantes contribuirão para o Programa e Projetos } \\
\text { vinculados, no planejamento, execução e avaliação? }\end{array}$ & 0,5 \\
\hline & & $\begin{array}{l}\text { 8.A proposta vincula as atividades de extensão ao Projeto Pedagógico do Curso - PPC } \\
\text { dos discentes, considerando o perfil do egresso? }\end{array}$ & 0,5 \\
\hline & \multirow{4}{*}{ Interação dialógica } & 9.A proposta explicita formas e grau de participação da comunidade no planejamento? & 0,5 \\
\hline & & 10.A proposta explicita formas e grau de participação da comunidade na execução? & 0,5 \\
\hline & & $\begin{array}{l}\text { 11.A proposta explicita a forma e grau de participação da comunidade na avaliação } \\
\text { final? }\end{array}$ & 0,5 \\
\hline & & 12.A proposta prevê parcerias com outros setores da sociedade? & 0,5 \\
\hline & $\begin{array}{l}\text { Interdisciplinaridade e } \\
\text { Interprofissionalidade }\end{array}$ & $\begin{array}{l}\text { 13.A proposta indica que haverá integração de diferentes áreas de conhecimento na } \\
\text { execução das atividades, seja por meio de participantes, unidades, parcerias ou pú- } \\
\text { blico-alvo envolvido? }\end{array}$ & 1 \\
\hline & $\begin{array}{l}\text { Indissociabilidade com } \\
\text { a pesquisa }\end{array}$ & 14.A proposta evidencia ações de pesquisa, busca e produção de conhecimento? & 1 \\
\hline & \multirow{3}{*}{ Aspectos Formais } & $\begin{array}{l}\text { 15.A proposta respeita o adequado enquadramento à modalidade de extensão es- } \\
\text { colhida? }\end{array}$ & 0,5 \\
\hline & & $\begin{array}{l}\text { 16.A proposta descreve como contribuirá para o Plano de Desenvolvimento da Insti- } \\
\text { tuição - PDI? }\end{array}$ & 0,5 \\
\hline & & $\begin{array}{l}\text { 17. A proposta apresenta carta de aceite da comunidade onde ocorrerá a ação onde } \\
\text { conste, no mínimo: Título da ação, Objetivos e período de execução previsto. }\end{array}$ & 0,5 \\
\hline
\end{tabular}




\begin{tabular}{|c|c|c|c|}
\hline & & $\begin{array}{l}\text { 18.As ações planejadas e as etapas de execução e avaliação das propostas estão coer- } \\
\text { entes com o orçamento previsto? }\end{array}$ & 0,5 \\
\hline \multirow{10}{*}{ 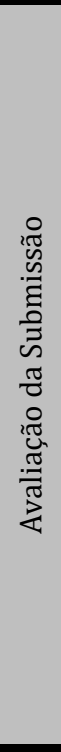 } & \multirow{2}{*}{ Ação de Extensão } & $\begin{array}{l}\text { 19.0s objetivos e resultados esperados para o período do edital estão coerentes com } \\
\text { as atividades planejadas? }\end{array}$ & 0,5 \\
\hline & & $\begin{array}{l}\text { 20.A proposta prevê a geração de produtos visando à ampliação de oportunidades ed- } \\
\text { ucacionais? }\end{array}$ & 1,5 \\
\hline & \multirow{7}{*}{ Proposta de Extensão } & $\begin{array}{l}\text { 21.Os produtos previstos poderão ser utilizados em outras comunidades, além da co- } \\
\text { munidade beneficiada pela ação de extensão? }\end{array}$ & 0,5 \\
\hline & & $\begin{array}{l}\text { 22.As despesas estão coerentes com as atividades planejadas para execução durante } \\
\text { o edital? }\end{array}$ & 0,5 \\
\hline & & $\begin{array}{l}\text { 23.0s objetivos do Plano de Trabalho do bolsista estão claros e coerentes com as ati- } \\
\text { vidades previstas para execução durante período do edital? }\end{array}$ & 1 \\
\hline & & $\begin{array}{l}\text { 24.0 Plano de Trabalho do Bolsista prevê a elaboração e apresentação de trabalho em } \\
\text { evento de extensão ou integrado de extensão e pesquisa? }\end{array}$ & 0,5 \\
\hline & & $\begin{array}{l}\text { 25.0 Plano de Trabalho expõe claramente a relação entre as atividades previstas e a } \\
\text { contribuição para a formação do acadêmico, considerando o perfil do egresso do Pro- } \\
\text { jeto Político Pedagógico do curso ao qual o aluno se vincula? }\end{array}$ & 0,5 \\
\hline & & $\begin{array}{l}\text { 26.Foi anexada carta de aceite da comunidade onde ocorrerá a ação onde conste, no } \\
\text { mínimo: Título da ação, Objetivos e período de execução previsto? }\end{array}$ & 0,5 \\
\hline & & 27.Qual a nota atribuída à ação de extensão na etapa de registro? & 3 \\
\hline & Coordenador & 28.Qual o nível de experiência em extensão universitária? & 1,5 \\
\hline \multirow{15}{*}{ 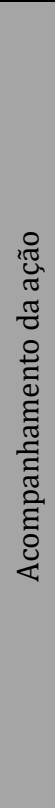 } & \multirow{5}{*}{$\begin{array}{l}\text { Avaliação do Coordena- } \\
\text { dor }\end{array}$} & $\begin{array}{l}\text { 29.Há a descrição das lições aprendidas com o projeto e das perspectivas de continu- } \\
\text { idade da ação? }\end{array}$ & 1 \\
\hline & & 30.Apresenta o Plano de Trabalho? & 0,5 \\
\hline & & 31.0 desempenho do acadêmico foi satisfatório? & 0,5 \\
\hline & & 32.As contribuições da ação para o aluno foram satisfatórias? & 0,5 \\
\hline & & $\begin{array}{l}\text { 33.A participação da comunidade externa/população atendida foi orientada no } \\
\text { planejamento, execução e avaliação das ações de extensão? }\end{array}$ & 0,5 \\
\hline & \multirow{6}{*}{$\begin{array}{l}\text { Avaliação do Acadê- } \\
\text { mico }\end{array}$} & 34. Apresenta o Plano de Trabalho? & 0,5 \\
\hline & & 35.0 desempenho do acadêmico foi satisfatório? & 0,5 \\
\hline & & $\begin{array}{l}\text { 36.Como avalia as contribuições da ação para a Formação Acadêmica, Profissional e } \\
\text { Cidadã? }\end{array}$ & 1 \\
\hline & & 37.0 desempenho do coordenador foi satisfatório? & 0,5 \\
\hline & & 38.0s resultados da ação no ano vigente foram satisfatórios? & 0,5 \\
\hline & & 39.Apresenta relato descritivo da experiência? & 1 \\
\hline & \multirow{4}{*}{$\begin{array}{l}\text { Avaliação da Comuni- } \\
\text { dade }\end{array}$} & $\begin{array}{l}\text { 40.A participação da comunidade externa/população atendida foi orientada no } \\
\text { planejamento, execução e avaliação das ações de extensão? }\end{array}$ & 1 \\
\hline & & $\begin{array}{l}\text { 41.0s resultados obtidos para a Comunidade/Público-Alvo foram efetivos e eficien- } \\
\text { tes? }\end{array}$ & 1 \\
\hline & & 42.0 desempenho do acadêmico foi satisfatório? & 0,5 \\
\hline & & 43. 0 desempenho do coordenador foi satisfatório? & 0,5 \\
\hline
\end{tabular}

Fonte: Elaborado pelas autoras (2019)

No que se refere às categorias de Registro e Editais, percebeu-se a falta de definição de práticas regulamentadas que norteiem o rumo que a instituição almeja para suas práticas extensionistas. Assim, entende-se que opção por formulários padronizados forneça maior dinamicidade ao processo de preenchimento das informações pelos propositores das ações, uma vez que desta forma eles têm clareza do que lhes é requisitado. 0 mesmo raciocínio é válido para os processos avaliativos, tendo em vista que facilitaria a análise dos itens padronizados e dispostos em uma ordem preestabelecida. Surge, assim, a primeira dimensão do modelo proposto, Registro da Ação que tem como responsável o Coordenador da Ação de Extensão. Essa dimensão refere-se à qualificação das ações, ao estabelecimento dos impactos, bem como ao planejamento detalhado, visando a facilitar a execução da ação e a futura emissão de relatórios. Nela também se avalia a indissociabilidade entre ensino, pesquisa e extensão e ações interdisciplinares e interprofissionais, que estejam alinhadas aos planos institucionais. Engloba ainda alguns aspectos formais da proposta. A partir das entrevistas, predominam, nessa dimensão, os aspectos relacionados às perspectivas do BSC de clientes e aprendizagem e crescimento.

A segunda dimensão, Avaliação da Submissão, deriva da ausência de critérios pontuáveis no registro da ação; enquanto que nos editais, considerando os recursos restritos, faz-se necessário o estabelecimento de critérios que permitam o ranqueamento das ações e a realização de um corte entre 
ações contempladas e não contempladas. Nessa dimensão, as questões referentes à geração de produtos, ao plano de trabalho do bolsista e à experiência do coordenador possuem um peso maior na avaliação, tendo em vista os impactos que tendem a gerar. Há também um peso elevado para as informações relativas ao registro da ação, tendo por objetivo estimular a qualificação das propostas e facilitar os processos de acompanhamento das ações nas fases posteriores. As análises das entrevistas refletem questões nessa dimensão que envolvem as quatro perspectivas do BSC.

Por fim, a dimensão Acompanhamento da Ação, origina-se do fato de a categoria Curricularização ter indicado que poucas instituições já regulamentam as atividades de extensão. Assim, a dimensão busca avaliar as ações de Extensão de maneira a contemplar o coordenador da ação, os acadêmicos e a comunidade beneficiada, ou seja, os principais clientes da extensão. A "Avaliação do Acadêmico" analisa o impacto na formação do estudante. Com relação ao critério "Avaliação do Coordenador", considerouse a reflexão sobre o que se pode aprender em relação à ação desenvolvida, facilitando a proposição e a condução de ações futuras. Quanto à "Avaliação da Comunidade", valoriza-se o processo dialógico entre comunidade e universidade e a geração de resultados que não se limitem ao ambiente acadêmico, propiciando efetivamente benefícios para o público abrangido pela ação.

Cada uma das 43 questões (Quadro 1) deve ser pontuada em escala de 0 a 10 pontos. A análise do modelo seguirá uma pontuação total de 0,00 (zero) a 10,00 (dez), conforme critérios e parâmetros de avaliação elencados na Figura 1, calculada pela somatória dos pontos atribuídos. Para ser aprovada a proposta deve obter nota (média ponderada) igual ou superior a 6,0 pontos nas Dimensões de Registro da Ação e Avaliação da Submissão. A análise e pontuação das dimensões devem ser de responsabilidade da Comissão de Extensão ou órgão equivalente na IES.

Figura 2. Parâmetros de avaliação de cada uma das dimensões e respectivas observações de análise

\begin{tabular}{|c|l|l|}
\hline Dimensão & Observações & Parâmetros de avaliação \\
\hline Registro da Ação & $\begin{array}{l}\text { Não deve ser permitida a aprovação de propostas que } \\
\text { tenham zerado a questão 8. }\end{array}$ & $\begin{array}{l}\mathbf{7 , 6} \text { a 10 - Excelente (Proposta atende a todos os aspectos } \\
\text { considerados neste quesito); } \\
\mathbf{5 , 1} \text { a 7,5 - Bom (Proposta atende a mais da metade dos aspectos } \\
\text { considerados neste quesito); } \\
\mathbf{2 , 6} \text { a 5,0 - Razoável (Proposta atende à metade dos aspectos } \\
\text { considerados neste quesito); }\end{array}$ \\
\hline $\begin{array}{c}\text { Avaliação da } \\
\text { Submissão }\end{array}$ & $\begin{array}{l}\text { Não deve ser permitida a aprovação de propostas que } \\
\text { tenham zerado as questões 20, 24 e 26. }\end{array}$ \\
\hline $\begin{array}{c}\text { Acompanhamento } \\
\text { da Ação }\end{array}$ & $\begin{array}{l}\text { A avaliação do acadêmico será realizada para cada melhorar muito (Proposta atende a menos da } \\
\text { acadêmico vinculado a avaliação e o cálculo da nota final } \\
\text { do critério “Avaliação do Acadêmico" deverá considerar a } \\
\text { média da notas dos acadêmicos. }\end{array}$ & $\begin{array}{l}\mathbf{0} \text { - Não consta (Proposta não atende a nenhum aspecto } \\
\text { considerado neste quesito). }\end{array}$ \\
\hline
\end{tabular}

Fonte: Elaborado pelas autoras (2019)

\section{Conclusões e contribuições tecnológicas e sociais}

Este estudo busca melhorar os processos de avaliação das ações de Extensão Universitária visando a propiciar maior clareza e segurança à comunidade envolvida com as práticas extensionistas. Valorizou-se o papel da comunidade atendida e dos acadêmicos em relação às ações de extensão. Compreende-se que a valorização da Extensão em equidade ao Ensino e à Pesquisa exige a criação de regramentos de progressão funcional do docente de maneira que tal política reflita a visão de uma IES disposta a produzir um estreitamento das relações universidade-sociedade.

Na gestão do modelo proposto, sugere-se que as instituições adaptem os parâmetros de classificação à demanda e estabeleçam regras específicas de classificação por edital. Assim, o parâmetro de corte de projetos (nota inferior a seis), os pesos e a aprovação segundo as melhores notas podem ser adaptados na medida em que a avaliação da extensão evolua no contexto da instituição. A critério das instituições, e na medida em que o modelo for implementado, podem ser utilizados tanto parâmetros qualitativos, como grupos de discussão da extensão universitária, quanto parâmetros quantitativos, como, por exemplo, a teoria da resposta ao item ou a análise fatorial para definição dos pesos mais adequados à avaliação da extensão.

Também é imprescindível a adequação dos sistemas das IES interessadas, para comportar todos os requisitos demandados, que suportarão a análise e emissão de pareceres e de relatórios para ações contempladas ou não com recursos de editais. Paralelamente, deve-se trabalhar institucionalmente a difusão dos critérios de avaliação dos projetos de Extensão, enfatizando a importância da clareza e precisão no preenchimento dos dados, bem como capacitando as partes (coordenadores e avaliadores) para a elaboração e planejamento das ações.

Entende-se que a adoção do modelo traria benefícios para todos os envolvidos na extensão. A im- 
plementação e gestão deveriam ficar a cargo da reitoria (pró-reitoria de extensão ou equivalente), enquanto o fornecimento das informações no sistema teria como responsável principal o coordenador da ação com a colaboração dos extensionistas e a sociedade beneficiada. A especificação e padronização dos critérios e o estabelecimento de pesos trazem clareza ao processo de concessão; e a existência de critérios de acompanhamento para as diferentes partes envolvidas permite uma avaliação ampla das ações.

\section{Referências}

Brasil (1988). Constituição da República Federativa do Brasil de 1988. Brasília. Recuperado em 01 de setembro de 2019, de http://www.planalto.gov.br/ccivil_03/Constituicao/Constituicao.htm.

Brasil (2010). Decreto no 7.233, de 19 de julho de 2010. Dispõe sobre os procedimentos orçamentários e financeiros relacionados à autonomia universitária, e dá outras providências. Brasília. Recuperado em 08 de janeiro de 2019, de https://www.planalto.gov.br/ccivil_03/_ato2007-2010/2010/decreto/d7233.htm.

Brasil (2012). Política Nacional de Extensão Universitária. Manaus. Recuperado em 03 de janeiro de 2019, de https://proex.ufsc.br/files/2016/04/Pol\%C3\%ADtica-Nacional-de-Extens\%C3\%A3o-Universit\%C3\%A1ria-e-book.pdf

Brasil (2014). Lei no 13.005, de 25 de junho de 2014. Aprova o Plano Nacional de Educação PNE e dá outras providências. Brasília. Recuperado em 13 de julho de 2019, de http://www.planalto.gov.br/ccivil_03/_ato2011-2014/2014/lei/l13005.htm.

Fórum de Pró-Reitores das Instituições Públicas de Educação Superior Brasileiras - FORPROEX. (2001). Avaliação Nacional da Extensão Universitária. Recuperado em 15 de janeiro de 2019, de https://www.ufmg.br/proex/renex/images/documentos/Avaliacao-Extensao.pdf

Gertler, P. J., Martinez, S., Premand, P., Rawlings, L. B., \& Vermeersch, C. M. J. (2015). Avaliação de Impacto na Prática. Grupo Banco Mundial: Washington, D.C.

Matos, E. \& Terra, R. (2015). Conceitos sobre eficiência. . In: Boueri, R., Rocha, F., \& Rodopoulos, F. (Orgs.). Avaliação da qualidade do gasto público e mensuração da eficiência. (cap. 6). Brasília: Secretaria do Tesouro Nacional.

Pereira, L. F. V. N. R. (2015). Um software livre para mensuração da eficiência. In: Boueri, R., Rocha, F. \& Rodopoulos, F. (Orgs.). Avaliação da qualidade do gasto público e mensuração da eficiência. (cap. 10). Brasília: Secretaria do Tesouro Nacional.

Veras, M. (2014). Gerenciamento de Projetos: Project Model Canvas (PMC). Rio de Janeiro: Brasport.

Zoghbi, A. C., Rocha, F., \& Mattos, E. (2013). Education production efficiency: Evidence from Brazilian universities. Economic Modelling, 31 (C), 94-103. 